
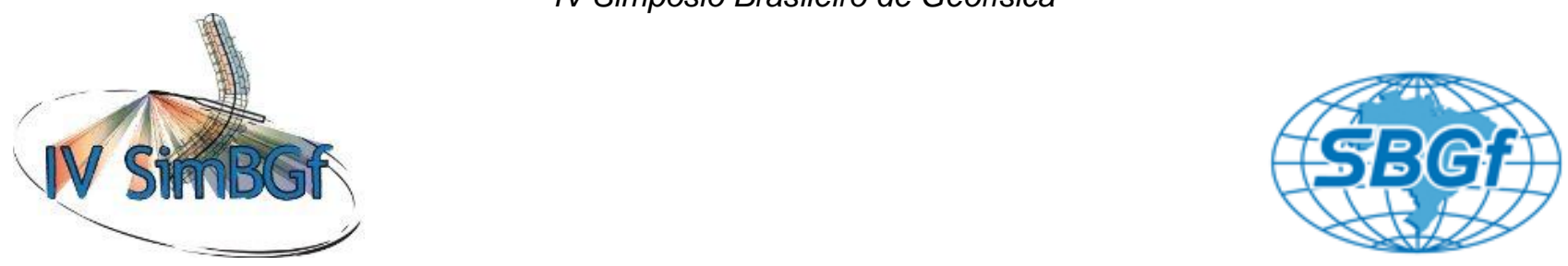

\title{
Detecção de Fraturas em Perfis Geofísico de Poço
}

Aldenize Ruela Xavier, Universidade Federal do Oeste do Pará Carlos Eduardo Guerra, Universidade Federal do Oeste do Pará André Andrade, Universidade Federal do Pará

Copyright 2008, SBGf - Sociedade Brasileira de Geofísica

Este artigo foi preparado para a apresentação no IV Simpósio Brasileiro de Geofísica Brasília, 14 a 17 de novembro de 2010. Seu conteúdo foi revisado pelo Comite Técnico do IV SimBGf, mas não necessariamente representa a opinião da SBGf ou de seus associados. É proibida a reprodução total ou parcial deste material para propósitos comerciais sem prévia autorização da SBGf.

\section{Resumo}

As questões relativas a geopressões são bem conhecidas na indústria do Petróleo e tem se tornado prioridade no mundo todo. Os estudos do histórico de produção de reservatórios fraturados mostram que as fraturas representam um importante papel na produtividade de formações com baixa permeabilidade. Isto porque, elas estabelecem uma rede de condutos hidráulicos entre o sistema de poros e o poço. Portanto, o conhecimento da localização e da atitude (direção e inclinação) das fraturas da parede do poço possibilita o desenvolvimento de estratégias de explotação, que podem potencializar a produção do poço, principalmente em ambientes de baixa permeabilidade, característico dos reservatórios carbonáticos. Este artigo apresenta uma metodologia de detecção das fraturas geológicas em perfis de imagem utilizando a morfologia matemática binária. A Morfologia Matemática tem sido utilizada como uma poderosa técnica de análise de imagens. Matheron e Serra introduziram um formalismo relacionado à teoria de conjuntos para a análise de imagens binárias sendo possível processá-las com operações simples como uniões, intersecções, complementações e translações.

\section{Introdução}

Para a indústria do Petróleo, atualmente, foi reacendido o interesse nos reservatórios carbonáticos (Akbar,2009). Neste tipo de rocha a avaliação de formação convencional tem sérios problemas quanto a determinação da relação entre a porosidade e a permeabilidade em função da ocorrência de porosidade na forma vulgular. Neste tipo de reservatório a conexão hidráulica é predominantemente formada por fraturas e microfraturas, que são as responsáveis diretas pela permeabilidade do reservatório. As ferramentas de perfilagem de poço formam um conjunto de imagens que podem ser usadas para interpretá-las, esta interpretação fica condicionada a perícia do intérprete. Este artigo apresenta uma metodologia que auxilia a identificação da presença e localização das fraturas em subsuperficie com a utilização da Morfologia Matemática Binária. A Morfologia não é apenas uma teoria matemática, mas uma poderosa técnica de análise de imagens. As origens da morfologia matemática são os estudos da geometria de mídia porosa na metade da década de 60 na França por G. Matheron e J. Serra. Eles introduziram um formalismo relacionado à teoria de conjuntos para a análise de imagens binárias sendo possível processá-las com operações simples como uniões, intersecções, complementações e translações.

\section{Metodologia/ Problema Investigado}

\subsection{A Morfologia Matemática Binária}

A morfologia matemática, ramo do processamento e da análise não linear de imagens, já é aplicada em várias áreas como biologia, metalografia, biomédica, visão robótica, controle de qualidade, reconhecimento de caracteres, etc. Em termos de imagens, a morfologia matemática permite processar imagens com objetivos de realce, segmentação, detecção de bordas, esqueletização, afinamento, análise de formas, compressão, etc. O que está sendo proposto é a implementação desta metodologia em perfis geofísico de poço a fim de dectar fraturas nas camadas atravessadas pelo poço.

O princípio básico da morfologia matemática consiste em extrair uma informação relativa, a geometria e a topologia de um conjunto desconhecido de uma imagem pela transformação a partir de um outro conjunto completamente definido chamado elemento estruturante. A partir do seu formato e tamanho temos a possibilidade de testar e de quantificar de que maneira o elemento estruturante, está ou não está contido na imagem.

Em processamento digital de imagens, funções e conjuntos são tratados de maneira muito semelhantes.

Definição 1: Definimos uma imagem em níveis de cinza como uma transformação do tipo $Z^{2} \rightarrow \mathbb{N}$, i.é, uma regra ou conjunto de regras que permite associar a cada par $(\mathrm{x}, \mathrm{y})$ de $Z^{\mathbf{2}}$ um "único" elemento $i$ natural de $N$.

Definição 2: O elemento estruturante é um conjunto completamente definido e conhecido (forma, tamanho), o qual é comparado com a imagem em estudo. O resultado desta comparação permite avaliar o conjunto desconhecido (Facon, 1996).

\subsection{Operadores morfológicos}


As operações básicas da morfologia matemática binária são a erosão, em que pixels que não atendem a um dado padrão são apagados da imagem, e dilatação, em que uma pequena area relacionada a um pixel é alterada para um dado padrão. Todavia, dependendo do tipo de imagem sendo processada (preto e banco, tons de cinza ou colorida) a definição destas operações muda, assim cada tipo deve ser considerado separadamente.

\section{Erosão}

Define-se a erosão de um conjunto $X$ pelo elemento estruturante B como:

$$
\operatorname{ero}^{B}(X)=\left\{x \in \varepsilon: B_{x} \subset X\right\}
$$

\section{Dilatação}

Define-se a operação de dilatação da seguinte maneira:

$$
\operatorname{dil}^{B}(X)=X \operatorname{dil} B=\left\{x \in X: B_{X} \cap X \neq 0\right\}
$$

\section{Abertura}

A aplicação de uma erosão imediatamente seguida por uma dilatação usando o mesmo elemento estruturante é referida como uma operação de abertura "opening". O nome abertura descreve o efeito dessa operação que tende a abrir pequenos vazios ou espaços entre objetos próximos numa imagem.

$$
a b e^{B}(X)=(X \Theta \bar{B}) \oplus B
$$

A operação abertura é usada também para remover ruídos da imagem. Pontos pretos aleatórios e isolados podem ser removidos pela erosão e a forma dos objetos é recuperada pela dilatação sem restaurar o ruído.

\section{Fechamento}

Um Fechamento é similar a uma abertura exceto que a dilatação é realizada primeiro seguida pela erosão usando o mesmo elemento estruturante.

$$
\operatorname{fec}^{B}(X)=(X \oplus \bar{B}) \Theta B
$$

Se uma abertura cria pequenos vazios na imagem, um Fechamento irá preencher ou fechar os vazios. A operação fechamento pode remover muitos dos pixels brancos relacionados a ruído.

\section{Resultados}

A figura 1 mostra um trecho de perfil de imagem de poço obtido através da ferramenta de perfilagem UBI

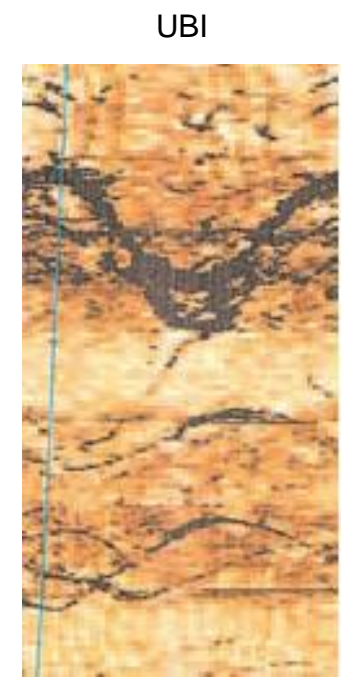

Figura 1 - Perfil de imagem obtido através da ferramenta UBI. (Adaptado de Akibar)

O problema aqui, consiste em identificar quais as fraturas que efetivamente induzirão melhor permeabilidade para a produção do poço.

A imagem colorida na figura 1, foi decomposta em três componentes R, G e B.
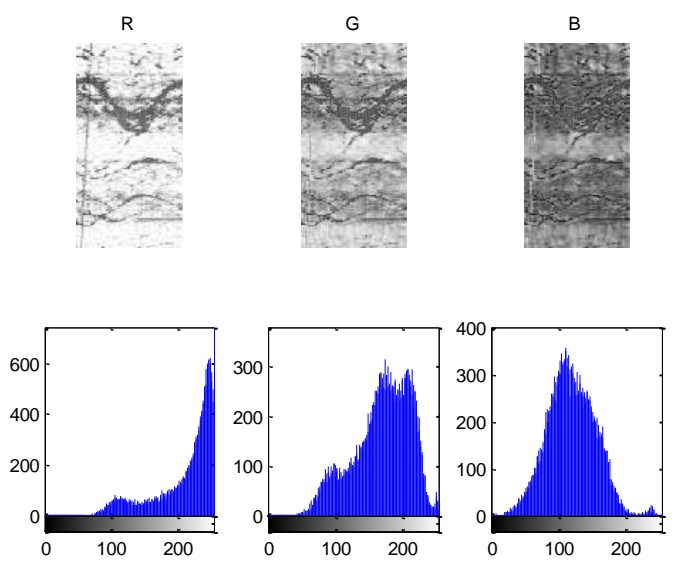

Figura 2: Decomposição RGB da imagem UBI, com seus respectivos histogramas.

Comparando estas três componentes com seus respectivos histogramas, as feições que se pretende destacar estão mais nítidas na componente $\mathrm{R}$ em tom de cinza, representadas na figura 2.

\section{Limiarização ou binarização}


Limiarizar a imagem constitui uma importante etapa para a implementação dos métodos de processamentos de imagens baseados na morfologia matemática. A limiarização consiste em converter uma imagem de níveis de cinza para uma outra imagem com apenas dois ND's.

O processo de binarização é uma transformação do tipo $\Psi: \mathrm{N} \rightarrow \mathrm{N}$ dada por :

$$
\begin{aligned}
& \psi: f \rightarrow f_{b} \\
& f_{b}=\psi(f)
\end{aligned}
$$

Em (3), $\Psi$ é a função que associa a cada valor ND de f, um único valor (0 ou 255).

os processos de limiarização tem como um de seus objetivos, tornar evidente ou explicito agrupamentos de pixel's contíguos que possuam características semelhantes. Na figura $3(A)$ tem-se a componente $R$ do perfil de imagem, já na figura $3(B)$ tem-se o resultado da binarização tendo como alvo as fraturas.
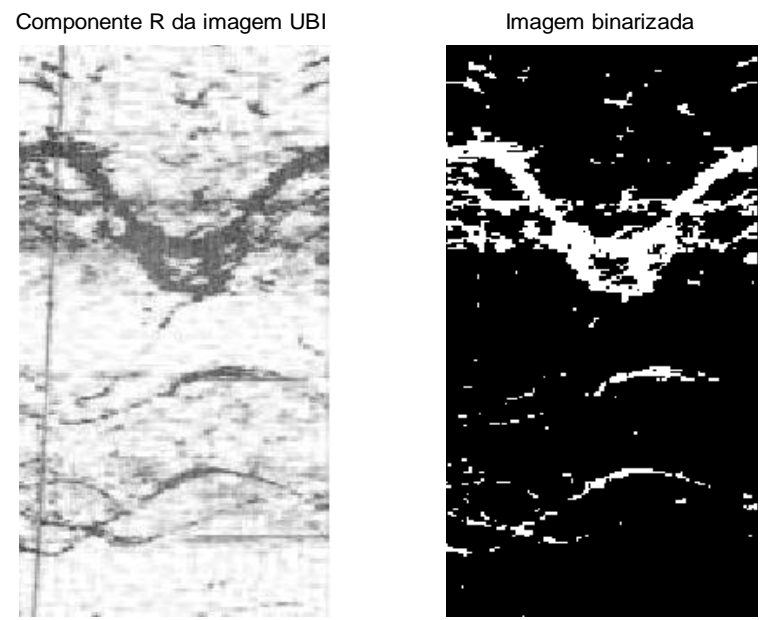

Figura 3 - (A) Imagem UBI em tom de cinza, (B) Imagem UBI binarizada.

$\mathrm{Na}$ Figura acima, pode-se observar que destacou nitidamente as zonas fraturadas mostradas na imagem $R G B$, e que aparece em tons opacos na imagem da banda $R$. Mas, percebe-se a presença de vários pontos espúrios que dificultariam o cálculo da área fraturada bem como da atitude da fratura.

Sendo assim, aplica-se o operador morfológico de fechamento sobre a imagem UBI binarizada mostrada figura 4 (B). O operador escolhido foi 0 elemento estruturante em linha com 5 vizinhanças. Este elemento se mostrou eficiente para eliminar os ruídos presentes na imagem e ainda preservar a feição da fratura. Como podemos observar na figura $4(\mathrm{C})$.

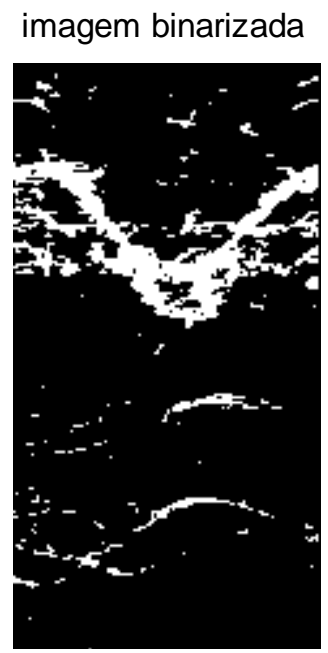

(A)
Imagem Fechada

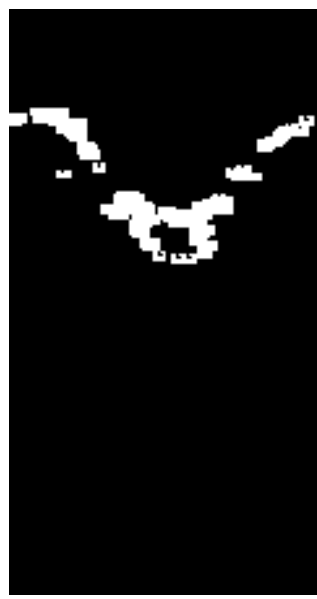

(B)
Figura 4 - (A) Imagem UBI binarizada, (B) Imagem após o operador morfológico de fechamento.

A detecção de borda, segundo Guerra (2007) é uma das aplicações mais importantes em processamento de imagens, pois nos remete a um conceito fundamental, i.é, "o conceito de contorno".A figura 5 mostra a imagem UBI original sobreposta pelos contornos das fraturas obtidos pela metodologia aplicada.

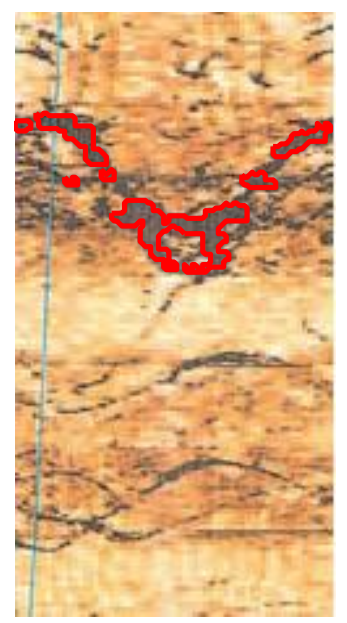

Figura 5 - Composição colorida da imagem do perfil de poço, com a sobreposição do contorno das fraturas obtidos apartir da metodologia proposta. 
Desta forma pode-se calcular a atitude da fratura, de modo, a estabelecer a influência que esta exercerá no ambiente, como por exemplo, a possibilidade de escoamento de fluidos. Porém, os resultados até agora obtidos não permitem determinar qual a extensão de prolongamento desta fratura, este cálculo só será possível com a correlação entre poços próximos.

\section{Inclinação da Fratura}

Para o trecho de perfil em estudo fez-se um ajuste de curvas nos pontos relacionados aos pixels da fratura identificada obtendo-se assim a curva em azul na Figura 6.

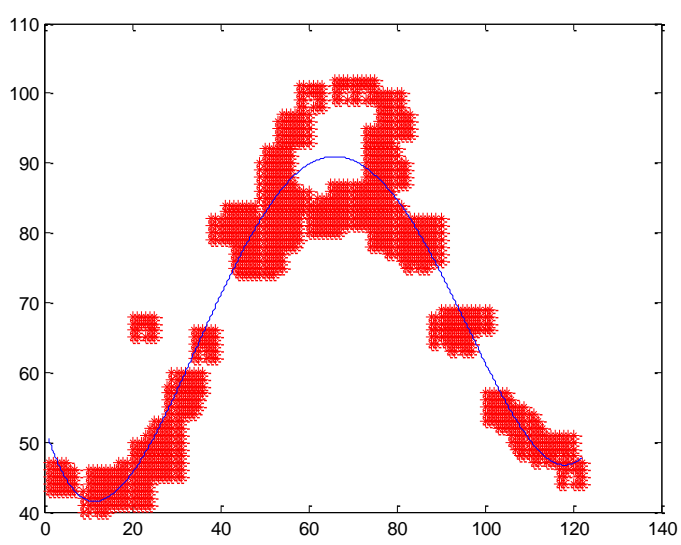

Figura 6: Ajuste de curva nos pontos representativos de pixels.

Desta forma, observa-se a continuidade da fratura mesmo em pontos descontínuos de pixels. Após a obtenção desta curva através de polinômio do $4^{\circ}$ grau, calcula-se a derivada para obter a inclinação de $-51 \%$, para esta fratura, considerando-se o poço vertical em relação a fratura.

\section{Discussão e Conclusões}

A base da morfologia consiste em extrair de uma imagem desconhecida a sua geometria através da utilização da transformação de uma outra imagem completamente definida, chamado elemento estruturante. A metodologia proposta aqui, mostra-se propícia para a caracterização de ambientes fraturados em perfis de imagem, pois possibilita a localização das fraturas. A escolha do elemento estruturante é determinante para qualidade das feições destacadas. A imagem processada já foi corrigida a priori em relação a inclinação do poço.A próxima etapa para o aperfeiçoamento da metodologia apresentada aqui consiste em automatizar a escolha deste elemento.

\section{Referências}

AKBAR, Mahmood; NURMI, Roy, STANDEN, Erick; SHARMA, Sandeep. Finding Fractures in deep formations. ONGC - Schlumberger Wireline Research Center.

BANON, G. J. F.; BARRERA, J. Bases da Morfologia Matemática para análise de imagens binárias - Recife, UFPE - DI, 1994, xii, 230p: il.

FACON, J. Morfologia Matemática: Teorias e Exemplos. Editora Universitária Champagnat da Pontifícia Universidade Católica do Paraná. Curitiba. 1996. xii. 320p: il. 